\title{
Characterization of a Mo Diffusion Barrier for Au/Sn Solder Bonding of Micro/Optoelectronic Devices to Carriers
}

\author{
A. He and D.G. Ivey \\ Department of Chemical and Materials Engineering, University of Alberta, Edmonton, Alberta, \\ Canada T6G 2G6
}

Gold-tin eutectic solders (30 at\% $\mathrm{Sn}$ ) are used for packaging microelectronic and optoelectronic devices, because of their excellent thermal and mechanical properties and relatively low melting or reflow temperature $\left(280^{\circ} \mathrm{C}\right)$. Electroplating is a cost effective alternative to current commercial solder deposition processes, such as solder preforms and evaporation. A coelectroplating process for depositing $\mathrm{Au} / \mathrm{Sn}$ alloys, from a slightly acidic, chloride-based solution using pulsed currents, onto metallized ceramic and semiconductor substrates has been developed [1,2]. Two separate Au/Sn compositions, 16 at\% Sn and 50 at\% Sn, can be deposited under appropriate plating conditions, i.e., current density, and pulse on/off time and duration. These compositions, according to the $\mathrm{Au}-\mathrm{Sn}$ phase diagram, correspond to $\mathrm{Au}_{5} \mathrm{Sn}$ and $\mathrm{AuSn}$, respectively. By using multiple current pulses and varying their duration, it is possible to deposit a composite solder structure with an overall composition ranging from $16-50$ at $\% \mathrm{Sn}$, including the important eutectic composition.

During chip bonding to carriers, such as $\mathrm{AlN}$ and $\mathrm{Al}_{2} \mathrm{O}_{3}$, there may be metallurgical reactions between the molten solder and the metallizations associated with both the carrier and the chip. The metallizations generally consist of an adhesion layer ( $\mathrm{Ti}$ or Ta in this work), a barrier and a capping layer $(\mathrm{Au})$. The capping layer will dissolve, at least partially, in the molten solder leaving the barrier exposed to the solder. The goal of this work is to assess the effectiveness of a Mo barrier in terms of its metallurgical behavior.

The metal layers were deposited by sputtering onto various substrates, including $\mathrm{AlN}, \mathrm{Al}_{2} \mathrm{O}_{3}$ and $\mathrm{Si}$. Silicon was used primarily for TEM analysis, as specimen preparation times (dimpling/sputtering) were reduced relative to those for samples using ceramic substrates. Different layer thicknesses were utilized for both the adhesion layer $(100-500 \mathrm{~nm})$ and the Mo diffusion barrier (100-250 $\mathrm{nm})$.

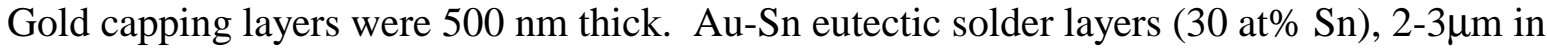
thickness, were deposited onto the metallizations by electroplating of $\mathrm{Au}_{5} \mathrm{Sn}$ and $\mathrm{AuSn}$ phases alternatively. One example on an $\mathrm{Al}_{2} \mathrm{O}_{3}$ substrate is shown in Fig. 1; the $\mathrm{Al}_{2} \mathrm{O}_{3}$ surface is quite rough, but good coverage for both the metallization and solder has been achieved. Sectioned samples were annealed in nitrogen at temperatures as high as $425^{\circ} \mathrm{C}$, which is well above the eutectic melting temperature $\left(280^{\circ} \mathrm{C}\right)$ for $\mathrm{Au}-\mathrm{Sn}$. As deposited and annealed samples were examined in cross section using SEM (Hitachi H2700 SEM or 4100 FESEM) and TEM (JEOL 2010).

Fig. 2 shows an SEM secondary electron (SE) image from a cleaved $\mathrm{Al}_{2} \mathrm{O}_{3}$ sample, with a Mo diffusion barrier, which had been annealed at $350^{\circ} \mathrm{C}$ for 30 minutes. The Au capping layer has been dissolved into the solder; however, the Mo barrier appears to be intact with uniform morphology. The barrier/solder interface was examined in more detail using TEM (Fig. 3). The TEM image (Fig. 3a) confirms that the entire Au capping layer was consumed by the molten solder, but the Mo was left unreacted with a distinct interface between it and the solder. EDX analysis of the solder and Mo 
layers close to the interface indicates no outward diffusion of Mo into the solder (Fig. 3b) and only a small amount of Au present at Mo grain boundaries (Fig. 3c); no Au was detected in the Mo grains.

References

[1] W. Sun and D.G. Ivey, U.S. Patent 6,245,208 (2001).

[2] B. Djurfors and D.G. Ivey, J. Electron. Mater. 30 (2001) 1249.

[3] This research was supported by the Natural Sciences and Engineering Research Council (NSERC) of Canada and Micralyne Inc. The assistance of S. Akhlaghi (Micralyne) and J.

Broughton (University of Alberta) in preparing the metallizations is gratefully acknowledged.

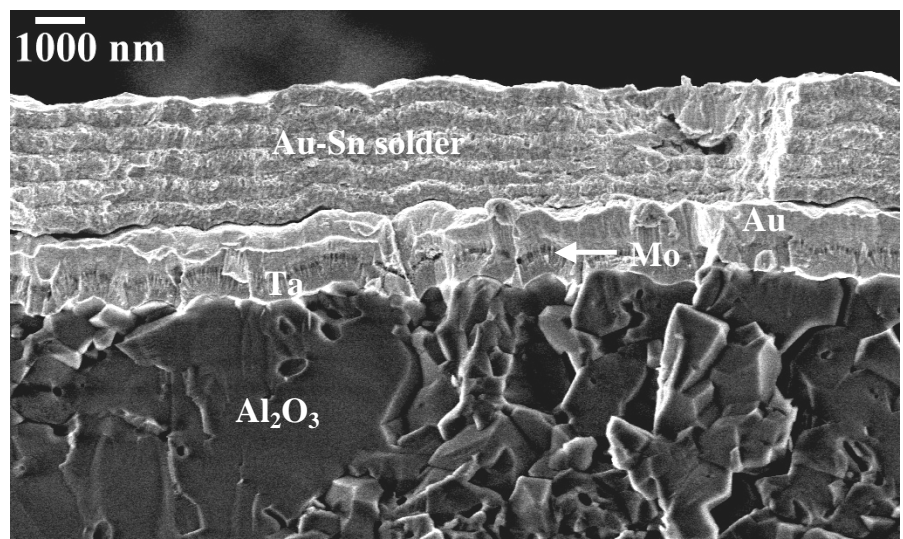

FIG. 1. SEM SE image of Au-Sn solder deposited on $\mathrm{Ta} / \mathrm{Mo} / \mathrm{Au}$ metallized $\mathrm{Al}_{2} \mathrm{O}_{3}$ substrate.

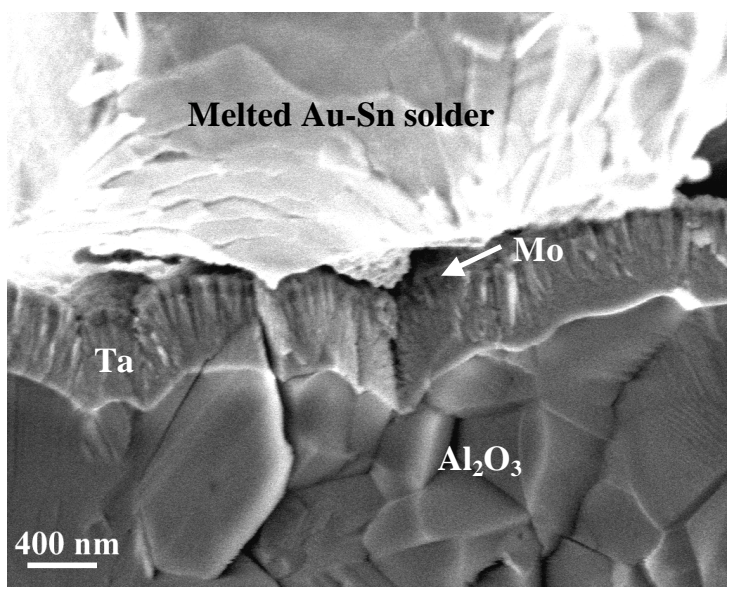

FIG. 2. SEM SE image of deposit in Fig. 1 , annealed at $350^{\circ} \mathrm{C}$ for 30 minutes.
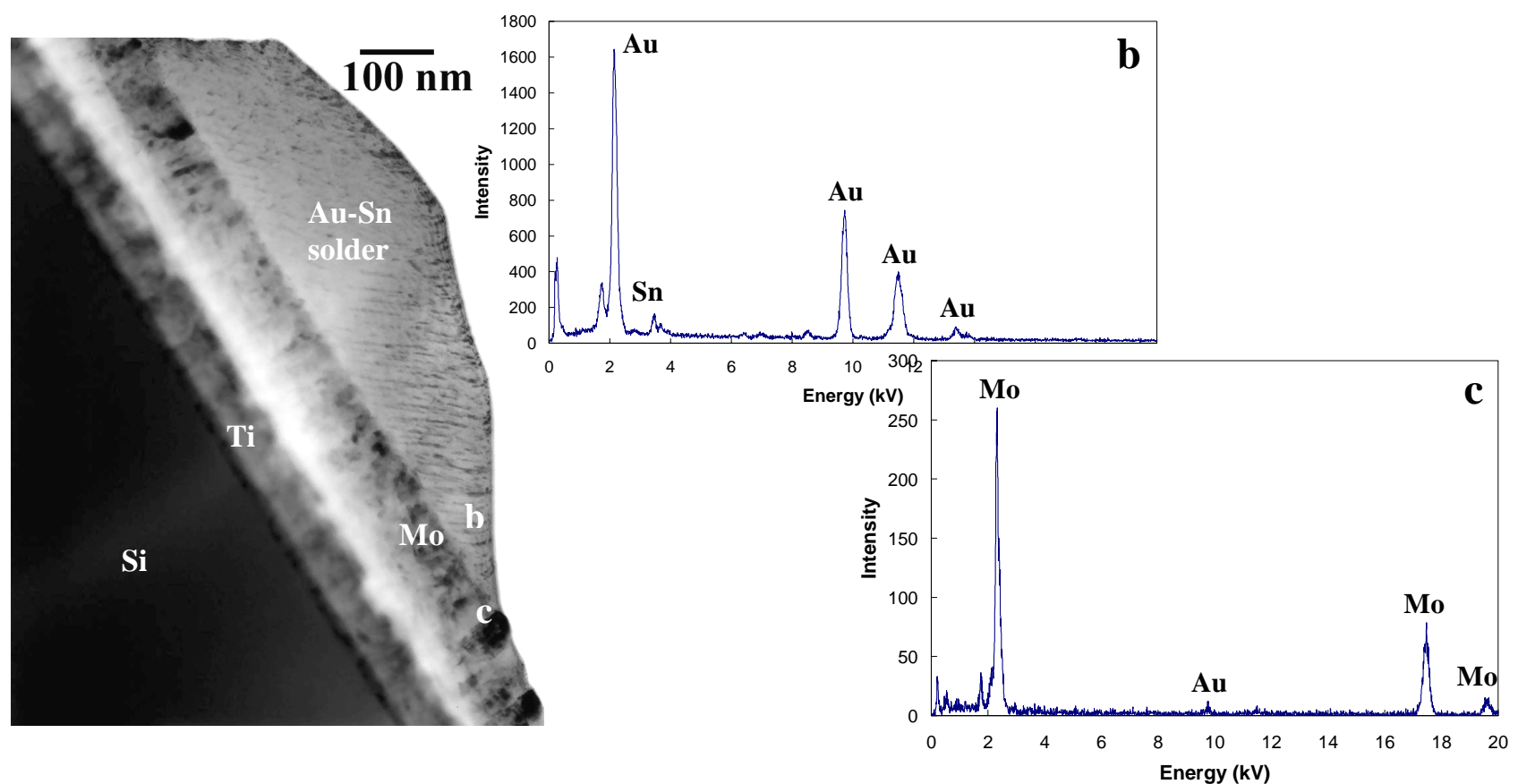

FIG. 3. a) TEM BF image of Ti/Mo/Au metallization, with electrodeposited Au-Sn solder, annealed at $400^{\circ} \mathrm{C}$ for 2.5 minutes. EDX spectra from areas indicated are shown in (b) and (c). 